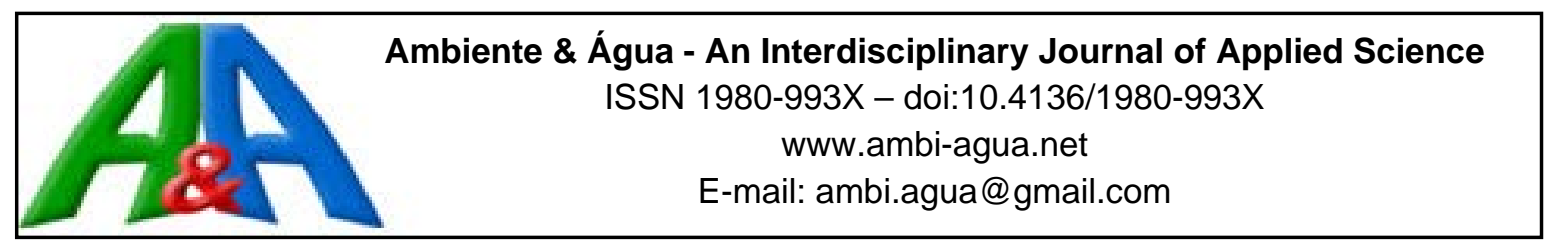

\title{
Biodegradação de polietileno e bioplástico no solo
}

\author{
doi:10.4136/ambi-agua.1919
}

Received: 13 Oct. 2016; Accepted: 11 Dec. 2016

\author{
Gustavo Tadeu Alvarenga Marques de Souza ${ }^{1 *}$; \\ Paulo Fortes Neto ${ }^{1}$; Nara Lúcia Perondi Fortes ${ }^{1}$; \\ Elizabeth da Costa Neves Fernandes de Almeida Duarte²; \\ Raquel Alexandra Cardoso Costa ${ }^{2}$; Artur Figueiredo Saraiva ${ }^{2}$ \\ ${ }^{1}$ Universidade de Taubaté (UNITAU), Taubaté, SP, Brasil \\ Programa de Pós-Graduação em Ciências Ambientais \\ ${ }^{2}$ Universidade de Lisboa, Lisboa, Portugal \\ Instituto Superior de Agronomia \\ *Autor correspondente: e-mail: gtamsouza@yahoo.com.br, \\ paulofortes.neto@gmail.com,nara_fortes@uol.com.br, eduarte@isa.ulisboa.pt, \\ raquelcosta@isa.utl.pt, artursaraiva@isa.ulisboa.pt
}

\section{RESUMO}

O filme de polietileno depois de utilizado como cobertura de solo ele é queimado com os restos culturais ou incorporado ao solo, pois a sua retirada do campo demanda custos com mãoobra. Uma alternativa para evitar este problema é substituir o polietileno pelo bioplástico, pois após o uso o bioplástico pode ser incorporado ao solo. Sendo assim, o estudo teve como objetivo avaliar a biodegradabilidade do polietileno e bioplástico no solo por meio das medidas de perdas de massa, liberação de C-CO $\mathrm{CO}_{2}$ e contagem de bactérias. Para a estimativa da perda de massa amostras de polietileno e bioplástico foram colocados em bolsas de náilon ( $2 \mathrm{~mm}$ ) e enterradas a 0,20 m profundidade do solo e periodicamente (30, 60, 90 e 120 dias) os filmes foram pesados para avaliar a perda de massa. A emissão de $\mathrm{C}-\mathrm{CO}_{2}$ e a contagem de unidade formadora de colônias de bactérias foram determinadas em amostras de solo incubadas com polietileno, bioplástico e celulose. A biodegradação do bioplástico estimada pela perda de massa foi igual a $37 \%$ e do polietileno foi de $1,2 \%$. A liberação de $\mathrm{C}-\mathrm{CO}_{2}$ e o número de bactérias foram mais elevados nos solos incubados com celulose e bioplástico.

Palavras-chave: atividade microbiana, decomposição, liberação de CO2.

\section{Polyethylene and bioplastic biodegradation in soil}

\section{ABSTRACT}

After being used as soil cover, polyethylene film is burned with the cultural remains or incorporated into the soil, since its removal from the field entails labor costs. An alternative to avoid this problem is to replace the polyethylene with bioplastic, because after use the bioplastic can be incorporated into the soil. This study therefore evaluated the biodegradability of polyethylene and bioplastic in soil by means of mass loss, $\mathrm{C}-\mathrm{CO}_{2}$ release and bacterial counting. In order to estimate the loss of mass, polyethylene and bioplastic samples were placed in nylon bags $(2 \mathrm{~mm})$ and buried at $0.20 \mathrm{~m}$ depth of soil and the films were periodically weighed (30, 60, 90 and 120 days) to evaluate the loss Of mass. The $\mathrm{C}-\mathrm{CO}_{2}$ emissions and the bacterial 
colony forming unit count were determined in soil samples incubated with polyethylene, bioplastic and cellulose. The biodegradation of the bioplastic estimated by the loss of mass was $37 \%$ and of the polyethylene was $1.2 \%$. The release of $\mathrm{C}-\mathrm{CO}_{2}$ and the number of bacteria were higher in the soils incubated with cellulose and bioplastic.

Keywords: $\mathrm{CO}_{2}$ evolution, decomposition, microbial activity.

\section{INTRODUÇÃO}

O consumo mundial de plásticos na agricultura atinge 6,5 milhões de toneladas por ano, sendo que $10 \%$ do consumo total são utilizados como cobertura do solo o que daria para recobrir uma área de 4,5 milhões de hectares (Scarascia-Mugnozza et al., 2006). Em 2004, 143 mil toneladas de plástico, foram utilizadas como cobertura de solo nos Estados Unidos da America e na Europa em 2011 foram utilizados 545.000 toneladas e os maiores consumidores foram Itália e Espanha e os menores consumidores foram Polônia e Benelux (Shogren e Hochmuth, 2004; Consórcio Agrobiofilm, 2013).

Devido ao aumento no uso de polietileno na agricultura o meio técnico vem questionando sobre o seu destino final, pois na maioria das propriedades rurais o plástico é queimado com os restos culturais e/ou fragmentado e misturado com o solo (Garthe e Kowal, 1993). Esta prática tem levado a comunidade científica a procurar estratégias para minimizar estes problemas ambientais e entre elas está a utilização de bioplásticos como cobertura de solo, pois o bioplástico por ter em sua composição polímeros biodegradáveis, tem como vantagem a possibilidade de ser incorporado e biodegradado pelos microorganismos do solo em dióxido de carbono, sais minerais e biomassa microbiana (Kyrikou e Briassoulis, 2007; Sivan, 2011; Kasirajan e Ngouajio, 2012).

A biodegradação do bioplástico ocorre porque o polímero orgânico presente na sua composição química é utilizado como fonte de energia e carbono pelos microorganismos do solo. O processo de decomposição é realizado por meio das seguintes etapas: quebra dos compostos de carbono em pequenas moléculas devido à secreção de enzimas e/ou pela ação do meio ambiente (temperatura, umidade e luz solar); absorção e transporte de pequenas moléculas para dentro das células dos microorganismos; e a oxidação das pequenas moléculas no interior das células microbianas em $\mathrm{CO}_{2}$, água e calor (ASTM, 2002; Kyrikou e Briassoulis, 2007; Sivan, 2011; Kasirajan e Ngouajio, 2012).

A biodegradação do bioplástico no solo é dependente das interações dos seguintes fatores: composição físico-química do polímero; condições climáticas; fertilidade, matéria orgânica, umidade, textura e microrganismos do solo (Olsen e Gounder, 2001; Casado 2009; Duarte et al., 2015; Adhikari et al., 2016). A esse respeito Casado (2009) avaliando a decomposição de poliéster biodegradável com e sem proteína de soja em sua composição, constatou que a taxa de conversão do carbono em $\mathrm{CO}_{2}$ foi maior no solo após a incorporação do poliéster contendo a proteína de soja, pois a proteína forneceu nitrogênio para os microorganismos acelerar a mineralização do carbono no solo. Olsen e Gounder (2001) utilizando bioplástico na cobertura do solo para a produção de hortaliças na Espanha constataram que $20 \%$ do bioplástico foi degradado em 33 dias no verão, 38 dias na primavera, 56 dias no outono e 83 dias no inverno. Duarte et al. (2015) avaliando a biodegradação do bioplástico em solos com diferentes textura e teor de matéria orgânica, observaram a que a biodegradação foi mais acentuada no solo com textura franco arenosa e maior conteúdo de matéria orgânica. Adhikari et al. (2016) estudando a relação entre os microrganismos do solo e biodegradação do bioplástico constataram que a taxa de degradação do bioplástico foi mais elevada no solo que apresentou o maior número de bactérias. 
No Brasil são raros os trabalhos realizados para avaliar a biodegradação do bioplástico no solo, sendo assim o presente estudo teve como objetivo avaliar a biodegradabilidade do bioplástico, a partir das estimativas de perdas de massas, liberação de $\mathrm{C}-\mathrm{CO}_{2}$ e contagem de bactérias no solo.

\section{MATERIAL E MÉTODOS}

O estudo foi conduzido na fazenda experimental do Departamento de Ciências Agrárias da

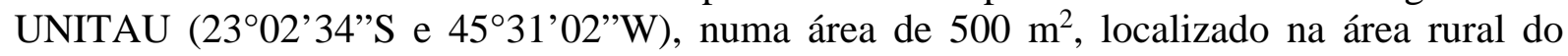
município de Taubaté, Estado de São Paulo, Brasil. A altitude média do local é de 577 m e, segundo a classificação de Köpen (1948), o clima é classificado de Cwa (Sub-tropical), com chuvas de verão e com uma precipitação média anual de $1300 \mathrm{~mm}$. O solo é classificado como sendo um Latossolo Vermelho Amarelo distrófico de textura média (Embrapa, 1999).

A biodegradabilidade no campo foi estimada pela perda de massa dos polímeros no solo, para isso, bolsas de náilon (malha de $2 \mathrm{~mm}$ ) com $15 \mathrm{~cm}$ de largura e $20 \mathrm{~cm}$ de comprimento contendo polietileno e bioplástico foram enterradas a $20 \mathrm{~cm}$ de profundidade do solo. Depois as bolsas foram retiradas nos períodos de 30, 60, 90 e 120 dias após serem enterradas no solo. As bolsas de náilon foram lavadas em água corrente para retirar o excedente de solo e abertas para retirar os polímeros. Os polímeros foram lavados com uma solução de $\mathrm{NaOH}(12 \%)$ para retirar as frações de argilas aderidas na superfície dos polímeros. Os polímeros foram colocados em uma estufa de ventilação forçada a $65^{\circ} \mathrm{C}$ e por 48 horas de secagem, posteriormente eles foram retirados e pesados para avaliar a perda de massa e comparar com o valor da massa determinada antes de enterrar os polímeros.

Para a determinação da biodegradação em laboratório pesou-se 100 mg de polietileno, bioplástico e celulose, depois de cortados em pedaços de $1 \mathrm{~mm}$ de diâmetro eles foram misturados com $100 \mathrm{~g}$ de solo. Após a mistura com o solo foi adicionado água destilada para ajustar a umidade do solo para 70\% da capacidade de retenção de água (CRA) e colocado dentro de um frasco de vidro (2L), ao lado do solo foi colocado um recipiente contendo $40 \mathrm{~mL}$ de solução de hidróxido de sódio $0,5 \mathrm{~mol} \mathrm{~L}^{-1}$ para absorver o $\mathrm{CO}_{2}$ liberado do solo. Os frascos de vidros, depois de fechados, foram levados para a incubação em uma sala climatizada à temperatura de $28^{\circ} \mathrm{C}$ e em ausência de luz durante um período de 15 dias. A cada intervalo de 3 dias foram realizadas as determinações da quantidade de $\mathrm{CO}_{2}$ liberado do solo por condutivimetria, conforme metodologia descrita por Rodella e Saboya (1999).

A contagem de bactérias foi realizada 30 dias após a mistura dos fragmentos de bioplástico, polietileno e celulose no solo. Para a quantificação foram pesadas $10 \mathrm{~g}$ de solo e colocadas em frascos com capacidade de $90 \mathrm{~mL}$, contendo solução salina esterilizada (solução tampão de Fosfato Monopotássico e Cloreto de Magnésio). A partir daí prepararam-se diluições sucessivas até $10^{-5}$, depois alíquotas de $0,1 \mathrm{~mL}$ foram transferidas para as placas de Petri contendo meio de cultura Bunt e Rovira (1955) e espalhadas com alça de Drigalski em triplicata. As placas foram mantidas a $28^{\circ} \mathrm{C}$ por 72 horas e depois efetuou-se a contagem das colônias e os resultados foram expressos em unidades formadoras de colônias por grama de solo seco (UFC x $10^{5} \mathrm{~g}^{-1}$ solo seco).

Os resultados da taxa acumulada de $\mathrm{C}-\mathrm{CO}_{2}$ e o número de bactérias foram submetidos à análise de variância e as médias comparadas pelo teste de Tukey a 5\% de probabilidade. E a análise de regressão foi realizada para estabelecer a relação de perda de massa do polietileno e bioplástico e a emissão de C-CO $\mathrm{CO}_{2}$ do solo incubados com polietileno, bioplástico e celulose com o tempo de decomposição. 


\section{RESULTADOS E DISCUSSÃO}

\subsection{Biodegradação dos polímeros no campo}

A Figura 1 apresenta a relação funcional da decomposição de massa dos polímeros de bioplástico e polietileno, em função do tempo, com as respectivas variações instantâneas de perda de massa durante 120 dias enterrados no solo. Verifica-se que a biodegradação foi mais acentuada no polímero de bioplástico, pois 30 dias após a incorporação no solo a taxa de biodegradação atingiu um valor de $20 \%$. Já no polímero de polietileno a biodegradabilidade foi mais lenta e começa a ser verificada após os 120 dias com uma taxa igual a 1,2\%, ao passo que no mesmo período a biodegradabilidade do bioplástico ficou em 37\%.

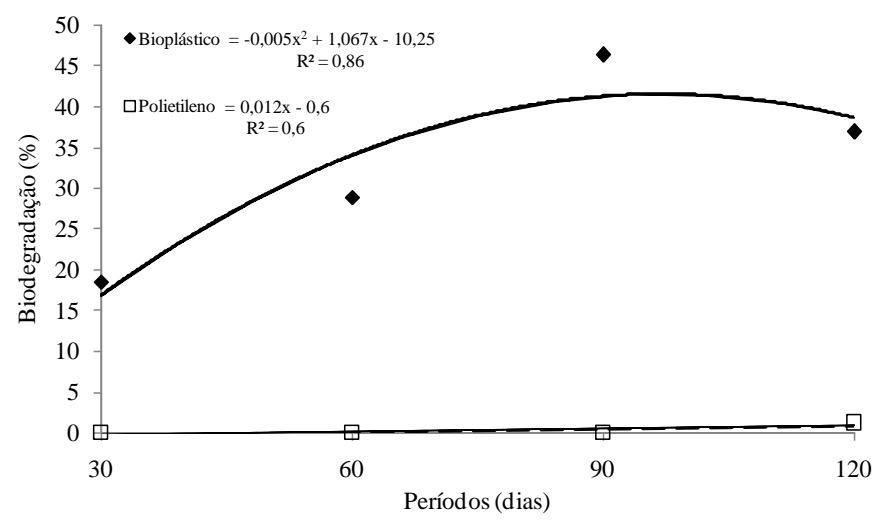

Figura 1. Percentual de biodegradação de polímeros de polietileno e bioplástico durante 120 dias incubação no solo.

Essa rápida decomposição do bioplástico em relação ao polietileno deve-se, provavelmente, à presença do amido na composição do bioplástico, pois o amido é um composto de carbono solúvel que em contato com os microorganismos irá aumentar a velocidade de biodegradação no solo (Sadi et al., 2010; Kasirajan e Ngouajio, 2012). Por outro lado, a lenta biodegradação do polietileno deve-se à presença de carbono recalcitrante ocasionada pela elevada cristalidade, hidrofobia e regularidade espacial dos polímeros existentes na composição do polietileno que contribuem para a sua resistência à biodegradação no solo (Bastioli, 1998).

A Figura 2 ilustra a biodegradabilidade do polímero de bioplástico retirado 60 dias após ser incorporado no solo, nota-se a descontinuidade e a fragmentação do filme ocasionada pela ação dos microorganismos do solo.

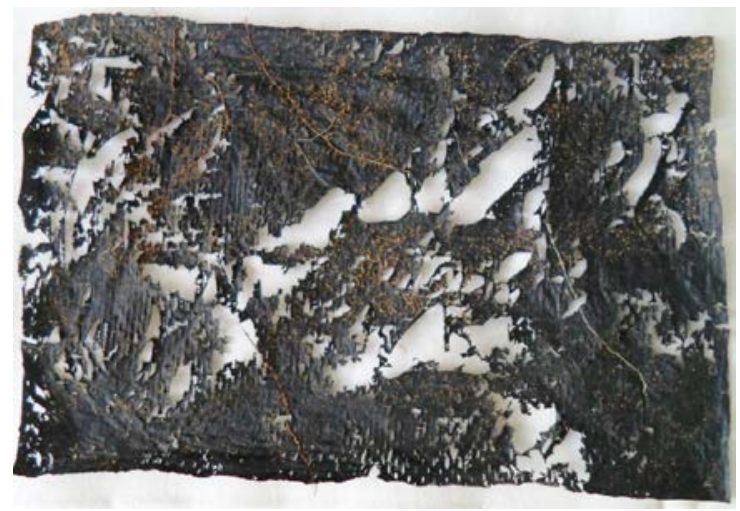

Figura 2. Polímero de bioplástico após 60 dias de incorporação no solo. 


\subsection{Biodegradação dos polímeros pela emissão do $\mathrm{C}-\mathrm{CO}_{2}$}

A Figura 3 apresenta a variação da emissão de $\mathrm{C}-\mathrm{CO}_{2}$ em amostras de solo misturadas com polietileno, bioplástico e celulose incubadas por um período de 360 horas. Verifica-se que a liberação de $\mathrm{C}-\mathrm{CO}_{2}$, nas 24 horas, mantém-se estável entre os tratamentos e, depois da 216 horas, a quantidade de $\mathrm{C}-\mathrm{CO}_{2}$ apresenta um aumento na modalidade no solo com celulose e bioplástico quando comparado com solo natural e solo incorporado com polietileno. Para o comportamento, observado na liberação de $\mathrm{C}-\mathrm{CO}_{2}$, entre a 24 e 216 horas, pode-se aventar que a causa seria a mudança no substrato energético, ou seja, a maioria dos microorganismos estabelecidos no solo não estava adaptada a decompor compostos orgânicos de baixa solubilidade fornecidos pela celulose e bioplástico. Já a tendência observada entre a 216 e 360 horas, pode estar relacionada às alterações das condições do meio, proporcionadas pela liberação de frações de carbono solúveis e nutrientes no solo. Esses fatores exigiram dos microorganismos um determinado tempo para adaptação das enzimas e ajustamento do metabolismo das células microbianas ao novo substrato orgânico e à nova condição química do solo (Fortes Neto, 2000; Bettiol e Fernandes, 2004).

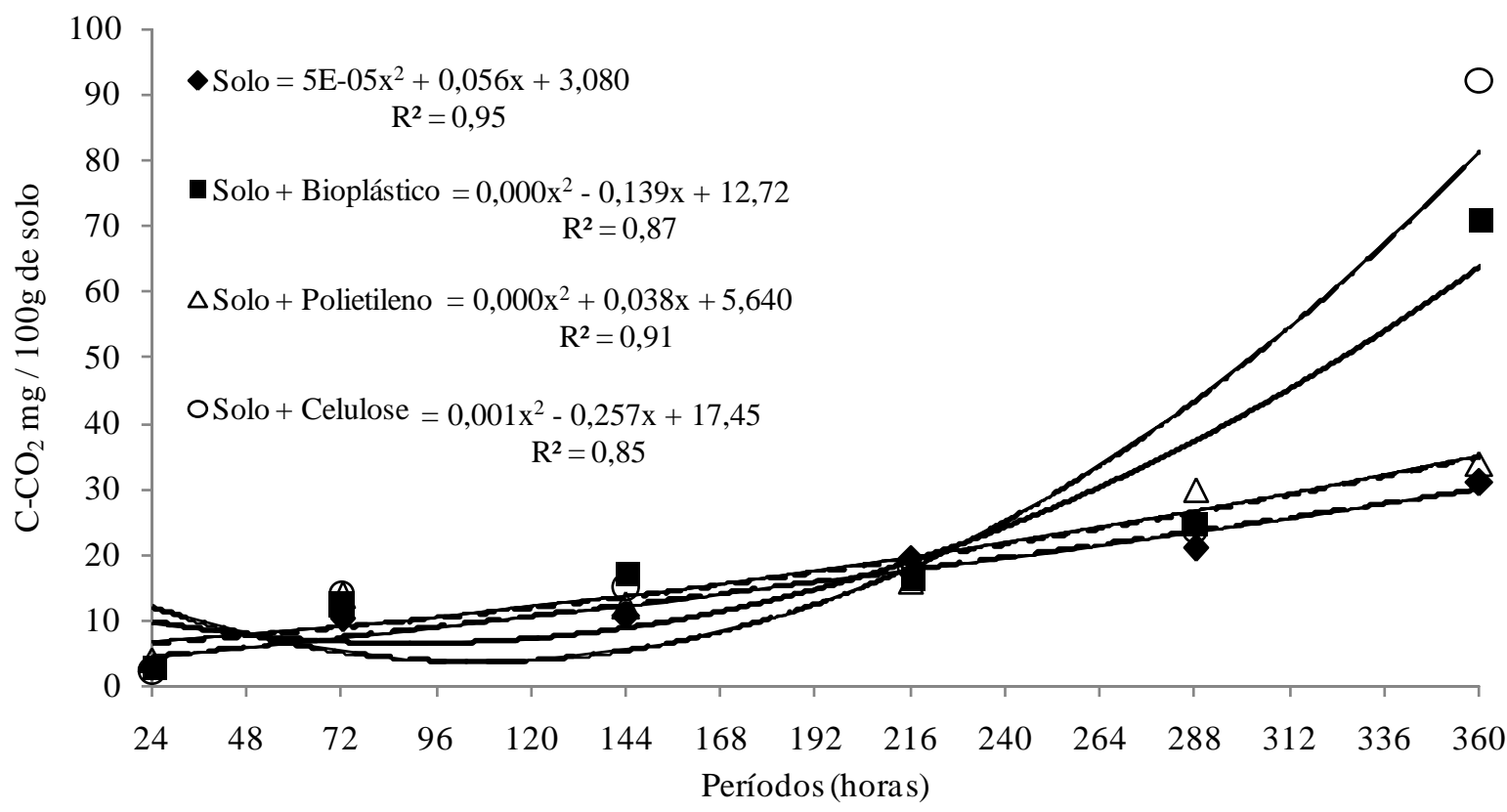

Figura 3. Variação da emissão do C- $\mathrm{CO}_{2}$ do solo misturado com polietileno, bioplástico e celulose incubados durante 360 horas.

Esses resultados sugerem que a incorporação da celulose e bioplástico no solo podem ter disponibilizado moléculas de carbono solúveis que foram rapidamente degradadas em glicose e assimiladas pelos microorganismos como fonte de energia, sendo convertidas em emissões de C-CO 2 (Bastioli et al., 1990, Kasirajan e Ngouajio, 2012).

Quanto à emissão de $\mathrm{C}-\mathrm{CO}_{2}$ no solo com polietileno verifica-se que ela mantém a mesma tendência da curva observada para o solo natural, indicando que no período de 360 horas o carbono existente no polietileno não ficou acessível para os microorganismos do solo.

A taxa acumulada da atividade respiratória dos microorganismos do solo foi expressa como mg de $\mathrm{C}-\mathrm{CO}_{2}$ liberado por 100 grama de solo, 360 horas após a incorporação de fragmentos de bioplástico, polietileno e celulose no solo (Figura 4). Os valores das emissões de $\mathrm{C}-\mathrm{CO}_{2}$ variaram significativamente com o tipo de substrato orgânico misturado ao solo. A quantidade de $\mathrm{C}-\mathrm{CO}_{2}$ acumulados variaram de $115,30 \mathrm{mg} 100 \mathrm{~g}^{-1}$ de solo para o solo natural a $165,30 \mathrm{mg}^{100 \mathrm{~g}^{-1} \text { de solo misturado com celulose. Observa-se que os menores valores de C-CO }}$ 
foram determinados no solo e no solo misturado com polietileno, e que os maiores valores foram observados nos solos misturados com celulose e bioplásticos. Resultados similares também foram observados por Saraiva et al. (2012), Costa (2012) e Duarte et al. (2015) quando, estudando a biodegradabilidade da celulose e bioplástico, constataram que quantidade de C$\mathrm{CO}_{2}$ liberado do solo incubado com celulose foi superior à determinada no solo com bioplástico.

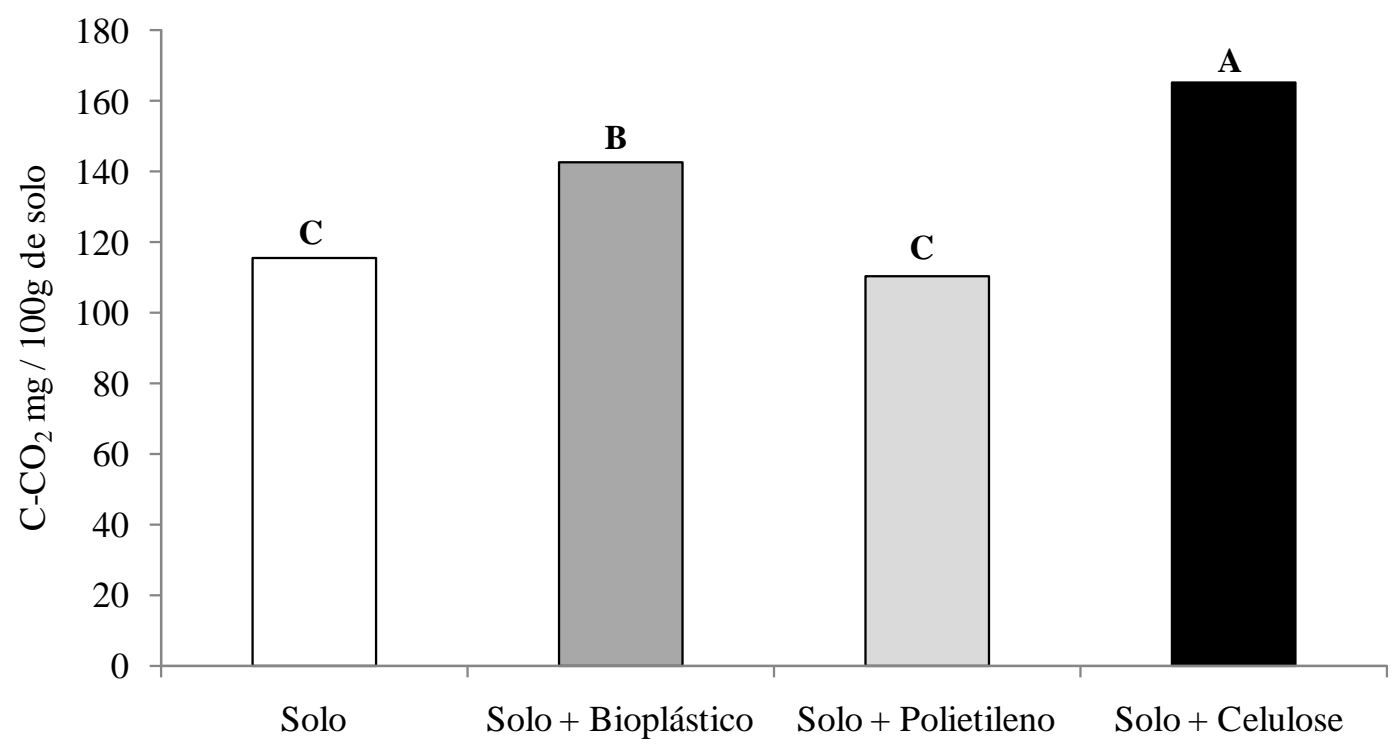

Figura 4. Taxa acumulada de $\mathrm{CO}_{2}$ liberado de amostras de solo misturado com polietileno, bioplástico e celulose durante 15 dias de incubação (Valores seguidos de mesma letra maiúscula, nas colunas, não diferem entre si pelo teste de Tukey 5\%).

As elevadas taxas de $\mathrm{C}-\mathrm{CO}_{2}$ verificadas nos solos incubados com celulose e bioplástico ocorreram devido à maior atividade biológica que, por sua vez, foi estimulada pela disponibilidade de carbono orgânico solúvel proporcionado pela decomposição da celulose e do amido presente no bioplástico (Sivan, 2011; Kasirajan e Ngouajio, 2012).

\subsection{Número de bactérias no solo}

A contagem de unidade formadora de colônia (UFC) de bactérias, realizada 15 dias após a mistura com os fragmentos de bioplástico, polietileno e celulose no solo, apresentou diferenças significativas entre os tratamentos, e os valores variaram entre $11 \times 10^{5} \mathrm{UFC} \mathrm{g}^{-1}$ de solo no solo sem mistura para $32 \times 10^{5} \mathrm{UFC} \mathrm{g}^{-1}$ de solo no solo misturado com celulose (Figura 5).

Comparando esses resultados com os valores verificados em áreas naturais e com cultivos agrícolas, constata-se que eles estão acima dos valores observados por Moura et al. (2015) em áreas sem intervenções antrópicas e abaixo dos valores determinados por Vieira e Nahas (2000) em áreas com cultivo agrícola, $10^{4}$ e $10^{7}$ respectivamente.

A análise da Figura 5 permite também verificar que o solo natural e o solo com a adição do polietileno apresentaram os menores números de bactérias. Por outro lado, nas amostras de solo com as misturas de bioplástico e celulose, constataram-se os maiores aumentos nos números de unidades formadoras de colônia de bactérias. Esses aumentos na contagem de bactérias, verificados nos solos incorporados com bioplásticos e celulose, podem ter ocorrido devido ao fornecimento de substratos energéticos e nutrientes provenientes da decomposição do bioplástico e celulose no solo, favorecendo, dessa maneira, a multiplicação das células bacterianas (Sivan, 2011; Kasirajan e Ngouajio, 2012; Adhikari et al., 2016). 


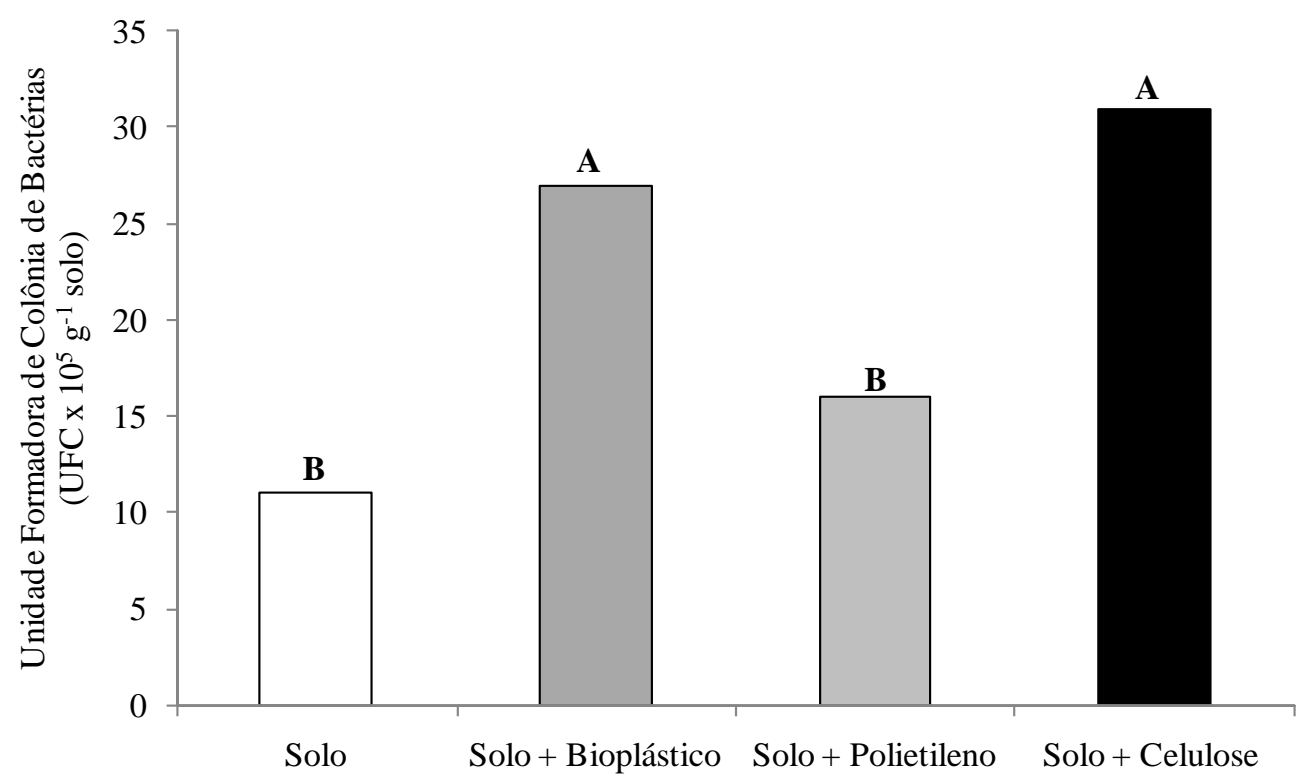

Figura 5. Unidade Formadora de Colônia (UFC) de bactérias x $10^{5} \mathrm{~g}^{-1}$ de solo determinada nas amostras de solo natural e misturada com bioplástico, polietileno e celulose. (Valores seguidos de mesma letra maiúscula, nas colunas, não diferem entre si pelo teste de Tukey 5\%).

\section{CONCLUSÃO}

Com base nos resultados pode-se concluir que:

- A biodegradação do bioplástico no solo determinada pela perda de massa em condição de campo foi mais acentuada do que a do polietileno.

- A curva de liberação do $\mathrm{C}-\mathrm{CO}_{2}$ do solo refletiu a pronta disponibilidade de carbono orgânico do bioplástico e celulose para os microrganismos do solo.

- A taxa de emissão de $\mathrm{C}-\mathrm{CO}_{2}$ foi mais elevada nas amostras de solo incubadas com bioplásticos e celulose do que no solo misturado com polietileno.

- O número de bactérias no solo com bioplástico e celulose foi mais elevado quando comparado com os valores determinados nas amostras de solo com polietileno e solo natural.

\section{AGRADECIMENTOS}

A Fundação AGRISUS - Agricultura Sustentável, pelo apoio e financiamento para a realização do Projeto Agrisus: 1351/14 e empresa SILVEX pela doação do bioplástico.

\section{REFERÊNCIAS}

ADHIKARI, D.; MUKAI, M.; KUBOTA, K.; KAI, T.; KANEKO, N.; ARAKI, K.S. et al. Degradation of bioplastics in soil and their degradation effects on environmental microorganisms. Journal of Agricultural Chemistry and Environment, v. 5, p. 23-34, 2016. http://dx.doi.org/10.4236/jacen.2016.51003

AGROBIOFILM CONSORCIUM. Agrobiofilm - compostable films for agriculture. [S.l.]: Silvex, Biobag \& ICSE, 2013.160 p. 
AMERICAN SOCIETY FOR TESTING AND MATERIALS - ASTM. Standard guide for conducting terrestrial plant toxicity tests, E. West Conshohocken, 1963-2002.

BASTIOLI, C.; BELLOTTI, V; GILLI G. The use of agricultural commodities as a source of new plastic materials.. In: APRIA CONFERENCE, 1990, Paris. Proceedings...: Biodegradable packagings and agricultural films. [S.l.:s.n.], 1990. p.1-36.

BASTIOLI, C. Properties and applications of Mater-Bi Starch-based materials. Polymer Degradation and Stability, v. 59, n. 1-3, p. 263-272,1998. http://dx.doi.org/10.1016/S0141-3910(97)00156-0

BETTIOL,W.; FERNANDES, S. A. P. Efeito do lodo de esgoto na comunidade microbiana e atributos químicos do solo. Jaguariúna: Embrapa Meio Ambiente, 2004. (Comunicado Técnico).

BUNT, J.S.; ROVIRA, A.D. Microbiological studies of some subantartic soils. Journal of the Soil Science, Oxford, v. 6, p.119-128. 1955

CASADO, E. B. Desenvolvimento e caracterização de blendas de poliéster sintético biodegradável com proteína de soja e estudo de biodegradação no solo. 2009. $94 \mathrm{f}$. Dissertação (Mestre em Engenharia Química) - Faculdade de Engenharia Química, Universidade Estadual de Campinas, Campinas, 2009.

COSTA, R. A. C. Estudo da biodegradabilidade de bioplásticos numa cultura de ciclo longo - morango. 2012. 75 f. Dissertação (Mestrado) - Instituto Superior de Agronomia, Universidade de Lisboa, Lisboa, 2012.

DUARTE, E.; SARAIVA, A.; COSTA, R.; FORTES NETO, P.; FORTES, N.; SOUZA, G. O papel do solo na biodegradação de filmes de cobertura biodegradáveis. In: O solo na Investigação Científica em Portugal. Lisboa: ISAPress, 2015. p. 49-52.

EMPRESA BRASILEIRA DE PESQUISA AGROPECUARIA - EMBRAPA. Sistema brasileiro de classificação de solos. Rio de Janeiro: Centro Nacional de Pesquisa de Solos, 1999. 412p.

FORTES NETO, P. Degradação de biossólido incorporado ao solo avaliada através de medidas microbiológicas. 2000. 113f. Tese (Doutorado) - Escola Superior de Agricultura “Luiz de Queiroz”, Universidade de São Paulo, Piracicaba, 2000.

GARTHE, J. W.; KOWAL, P. D. Recycling used agricultural plastics. Penn State Fact Sheet C-8. 1993. Disponível em: http://pubs.cas.psu.edu/freepubs/pdfs/C8.pdf. Acesso em: 23 maio 2016.

KASIRAJAN, S.; NGOUJIO, M. Polyethylene and biodegradable mulches for agricultural aplicattions: a review. Agronomy for Sustainable Development, v. 32, p. 501-529, 2012. http://dx.doi.org/10.1007/s13593-011-0068-3

KÖPPEN, W. Climatologia: con un estudio de los climas de latierra. Cidade do México: Fondo de Cultura Econômica, 1948. 479 p.

KYRIKOU, I.; BRIASSOULIS, D. Biodegradation of agricultural plastic filmes: a critical review. Journal Polymer Environment, v. 15, p. 125-150, 2007. http://dx.doi.org/10.1007/s10924-007-0053-8 
OLSEN, J. K.; GOUNDER, R. K. Alternatives to polyethylene mulch film - a field assessment of transported materials in capsicum (Capsicum annuum L.). Australian Journal of Experimental Agriculture, v. 41, p. 93-103, 2001. http://dx.doi.org/10.1071/EA00077

RODELLA, A. A.; SABOYA, L. V. Calibration for conductimetric determination of carbon dioxide. Soil Biology and Biochemistry, v. 31, p. 2059-2060, 1999.

SADI, R. K.; FECHINE, G. J. M.; DEMARQUETTE, N. R. Photodegradation of poly (3hydroxybutyrate). Polymer Degradation Stability, v. 95, n. 12, p. 2318-2327, 2010. http://dx.doi.org/10.1016/j.polymdegradstab.2010.09.003

SARAIVA, A.; COSTA, R.; CARVALHO, L.; DUARTE, E. The use of biodegradable mulch films in muskmelon crop production. Basic Research Journal of Agriculture Science and Review, v. 14, p. 88-95, 2012.

SCARASCIA-MUGNOZZA, G.; SCHETTINI, E.; VOX, G.; MALINCONICOM, M.; IMMIRZI, B.; PAGLIARA, S. Mechanical properties decay and morphological behaviour of biodegradable films for agricultural mulching in real scale experiment. Polymer Degradation Stability, v. 91, p. 2801-2808, 2006. http://dx.doi.org/10.1016/j.polymdegradstab.2006.02.017

SHOGREN, R. L.; HOCHMUTH, R. C. Field evaluation of watermelon grown on paperpolymerized vegetable oil mulches. HortScience, v. 39, p. 1588-1591, 2004.

SIVAN, A. New perspectives in plastic biodegradation. Current Opinion in Biotechnology, v. 22, p. 422-426, 2011. http://dx.doi.org/10.1016/j.copbio.2011.01.013

VIEIRA, F. C. S.; NAHAS, E. Quantificação de bactérias totais e esporuladas no solo. Scientia Agrícola, v. 57, p. 539-545, 2000. http://dx.doi.org/10.1590/S0103-90162000000300026 